\title{
Study on Change of Topography in Water Area with Field Measurement
}

\author{
Satoshi Iwakami1 ${ }^{1}$ Masahiko Tamega ${ }^{1}$, Masahide Sanada', Michiaki Mohri' ${ }^{1}$, Yoshitaka Iwakami1, \\ Naoki Okamoto', Shuji Jimbo², Masaji Watanabe ${ }^{2 *}$ \\ ${ }^{1}$ Earth Rise Company, Inc., Okayama, Japan \\ ${ }^{2}$ Okayama University, Okayama, Japan \\ Email: *watan-m@okayama-u.ac.jp
}

How to cite this paper: Iwakami, S., Tamega, M., Sanada, M., Mohri, M., Iwakami, Y., Okamoto, N., Jimbo, S., \& Watanabe, M. (2021). Study on Change of Topography in Water Area with Field Measurement. Journal of Geoscience and Environment Protection, 9, 221-226.

https://doi.org/10.4236/gep.2021.94014

Received: March 23, 2021

Accepted: April 37, 2021

Published: April 30, 2021

\begin{abstract}
Disastrous flood events in recent years include 2018 Japan floods (July 2018), Typhoon 19 (Hagibis, October 2019) and the following heavy rain event, and July 2020 heavy rain disaster. Such disastrous flood events are expected to occur more frequently as the climate change progresses, and it is indispensable to update information regarding water areas such as rivers, reservoirs, and coastal waters. This study demonstrates practical techniques to analyze underwater topography. Longitude and latitude components of ellipsoidal data recorded by a GPS receiver are projected to a rectangular coordinate system, and results are combined with vertical components including data recorded by an echo sounder unit so that tracks on an underwater floor are obtained. A mapping on a finite dimensional space of continuous functions over a triangular mesh is formulated, and its fixed point gives rise to an underwater floor that fits the tracks. Our techniques are illustrated with data obtained in measurement conducted in a reservoir called Kojima Lake located in Okayama Prefecture, Japan.
\end{abstract}

\section{Keywords}

Underwater Topography, RTK-GPS, Echo Sounder, Triangular Mesh, Fixed Point Iteration

\section{Introduction}

The 2018 Japan floods caused severe damages including 119 fatalities, 29 wounded, 213 totally destroyed houses, 340 partially destroyed houses, and 290 damaged houses (Ministry of Land, Infrastructure, Transport and Tourism, 2018). Damages due to the 2019 Typhoon 19 and related heavy rain falls include 
104 people killed, 3 people missing, 43 people severely wounded, 341 people minorly wounded, 3308 houses totally destroyed, 30,024 houses partially destroyed, and 12,510 minorly damaged (Cabinet Office, Government of Japan, 2019). Damages due to the July-2020 heavy rain disaster include human damages of 84 fatalities, 2 missing people, 1621 totally destroyed houses and 4504 partially destroyed houses (Cabinet Office, Government of Japan, 2021). As the climate change progresses, disastrous heavy rain events may increase in frequency and scale, and the preventive maintenance of rivers, reservoirs, and coastal areas as well as measurement and analysis for underwater topography are necessary.

This study focuses on techniques for measurement and analysis of underwater topography. The following sections illustrate techniques to generate a surface from a given set of data points. Those techniques were applied to positional data and depth data obtained in measurement conducted in a lake called Kojima Lake. Positional data obtained from a RTK-GPS (real time kinematic-global positioning system) in VRS (virtual reference station) mode. The Gauss-Krüger projection was applied to horizontal coordinates of the positional data, and resultant data combined with depth data obtained from an echo sounder unit leads to a curve in an underwater topography was obtained. A piecewise linear function defined on a triangular mesh on the plane represents a surface that fits outputs from the measurement. The least square approximation on each element led to a mapping on the nodal values. A fixed point iteration of the mapping gave rise to a surface that fit the data.

\section{Use Output from Measurement}

Measurement was conducted in a reservoir called Kojima Lake, Okayama Prefecture, Japan on December $26^{\text {th }}, 2020$ and January $27^{\text {th }}, 2021$. A GPS antenna was attached to the upper end of a pole fixed to a boat. An oscillator unit of echo sounder was attached to the lower end of the pole submerged underwater (Figure 1). As the boat navigated, positional data output from the GPS unit and depth data output from echo sounder unit were recorded.

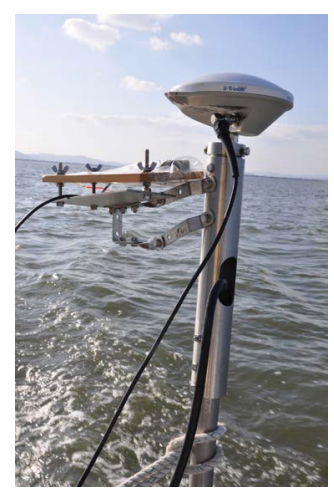

(a)

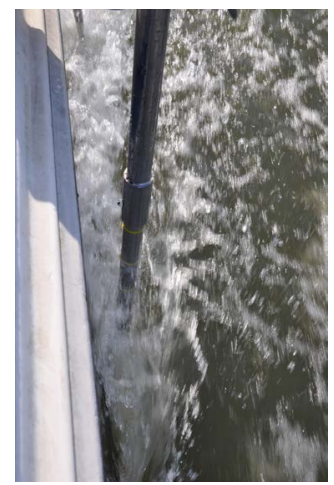

(b)

Figure 1. (a) GPS antenna attached to the upper end of pole fixed to a boat; (b) An oscillator unit was attached to the lower end of the pole submerged underwater. The photographs were taken in the measurement conducted on January $27^{\text {th }}, 2021$. 
The Gauss-Krüger projection was applied to horizontal coordinates of the positional data (Figure 2). The positional data were combined with depth data, and curves in the underwater topography were generated (Figure 3 ).

\section{Construction of Underwater Topography by Fixed Point Iteration}

Construction of underwater topography based on results from measurement involves nested iterative processes, iteration of mesh division and iteration of nodal values. First, iteration of nodal value is described. Consider a triangular mesh consisting of $m$ elements and $n$ nodes. Given data points whose $x, y$ components are contained in the triangular mesh, our problem is to construct a surface that fits the data points. Consider a single element, which we call element $k$, with vertices $\left(x_{1}, y_{1}\right),\left(x_{2}, y_{2}\right)$, and $\left(x_{3}, y_{3}\right)$. Suppose that the element $k$ contains $(x, y)$ components of the $l$ data, $\left(x_{1}, y_{1}, z_{1}\right),\left(x_{2}, y_{2}, z_{2}\right), \cdots,\left(x_{l}, y_{l}, z_{l}\right)$. Note that those data include $\left(x_{1}, y_{1}, z_{1}\right),\left(x_{2}, y_{2}, z_{2}\right)$ and $\left(x_{3}, y_{3}, z_{3}\right)$ whose $x, y$ components are coordinates of the vertices. Consider the graph of a linear function $z=a x+b y+c$ such that the values of coefficients $a, b$, and $c$ are those that minimize the square sum

$$
\sum_{j=1}^{l}\left[z_{j}-\left(a x_{j}+b y_{j}+c\right)\right]^{2}
$$

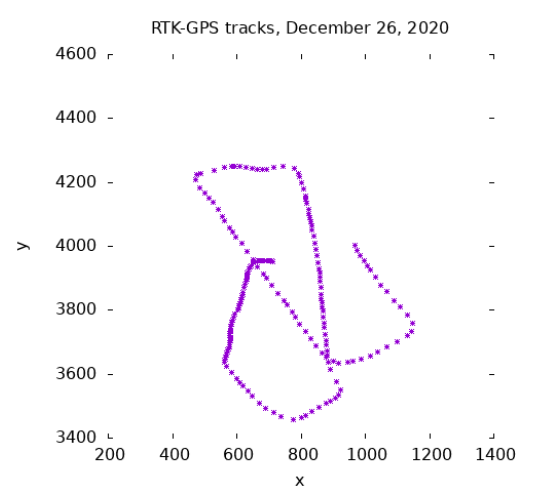

(a)

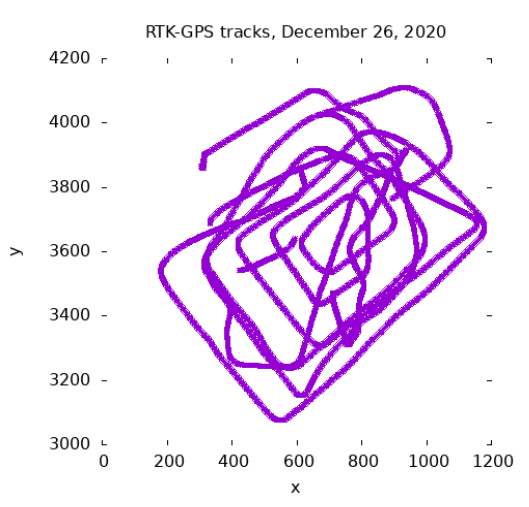

(b)

Figure 2. GPS tracks (a) December $26^{\text {th }}, 2020$, (b) January $27^{\text {th }}, 2021$.

Topographic data, December 26, 2020

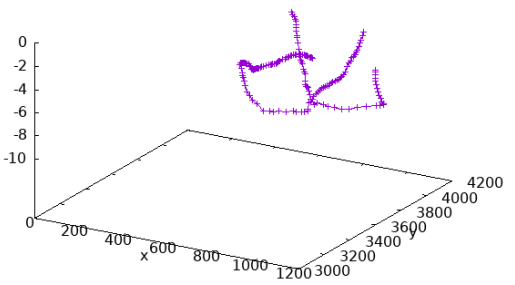

(a)

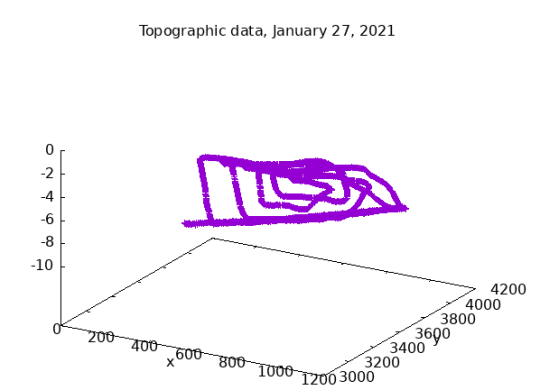

(b)

Figure 3. Curves on underwater topography. (a) December $26^{\text {th }}, 2020$, (b) January $27^{\text {th }}$, 2021. 
Once those coefficients are evaluated, new value of $z_{1}, z_{1}=a x_{1}+b y_{1}+c$. is set. With this new value of $Z_{1}$, the operation is repeated to update the value of $z_{2}$, and then with those new values of $z_{1}$ and $z_{2}$, the operation is repeated to update the value of $z_{3}$. After those operations are completed for the element $k$, the operations are repeated for the element $k+1$.

Let $z^{k}$ be the $n$ dimensional vector whose components are nodal values $Z_{1}{ }^{k}$, $Z_{2}{ }^{k}, \ldots, Z_{m}{ }^{k}$ after $k^{\text {th }}$ iteration. The iteration is terminated when the residual error between two successive approximations reaches a prescribed value $\varepsilon$, that is,

$$
\left\|\mathbf{z}^{k}-\mathbf{z}^{k-1}\right\|=\sqrt{\sum_{i=1}^{n}\left(z_{i}^{k}-z_{i}^{k-1}\right)^{2}}<\varepsilon .
$$

In this study $\varepsilon=0.01$.

A triangular mesh, Mesh 0, that contains significant GPS tracks was set. A triangular mesh is constructed from an original mesh iteratively. Denote by Mesh 1 the triangular mesh obtained after $I$ iterations. At each iteration, every element is divided into four elements. Figure 4 shows mesh 0 and mesh 5 . Figure 5 shows the surface over mesh 5 . The surface was obtained after 130 iterations.

Our techniques were reapplied to the data obtained in the measurement conducted on December 26 $6^{\text {th }}, 2019$ and January 6 ${ }^{\text {th }}, 2020$ (Iwakami, et al., 2020). Figure 6 shows the difference between the result and the result shown in Figure 5.

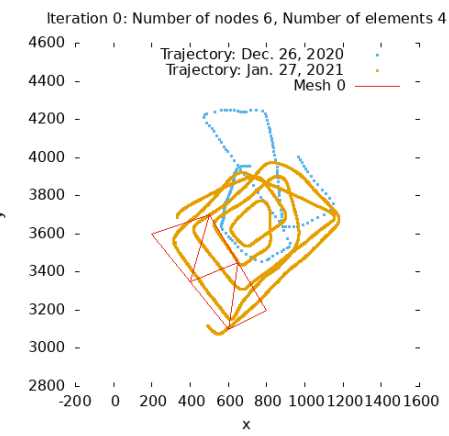

(a)

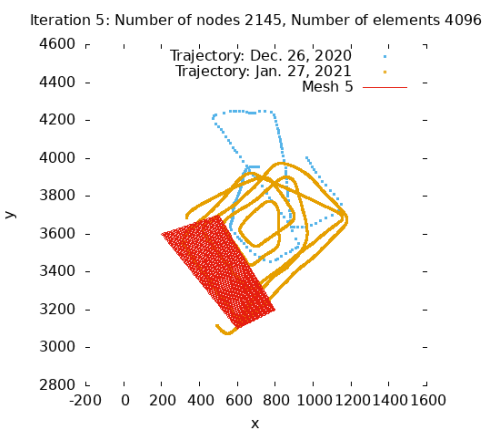

(b)

Figure 4. (a) Mesh 0 and (b) Mesh 1 . The RTK-GPS trajectories are also shown.

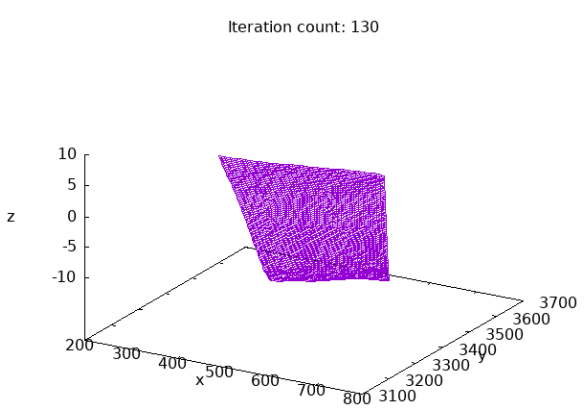

(a)

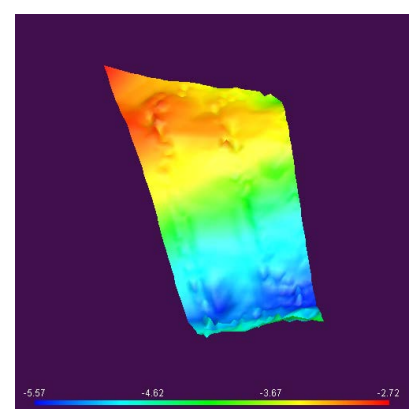

(b)

Figure 5. (a) Piecewise linear surface over Mesh 5 after 130 iterations. (b) Surface colored according to altitude. 


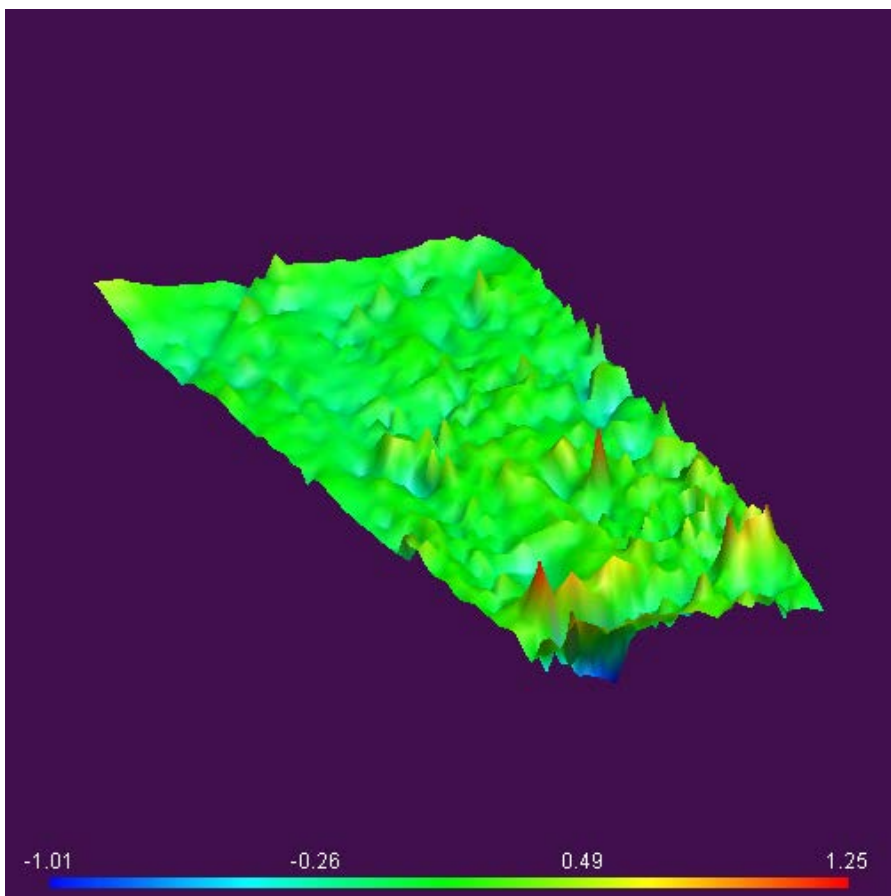

Figure 6. Sedimentation over the period January 2020-December 2020.

\section{Discussion}

Our result shows the significant erosion in the region during the period January 2020-December 2020. The total sedimentation in the region during the period is approximately $10,041 \mathrm{~m}^{3}$. On the other hand, the total area of the region is $160,000.00 \mathrm{~m}^{2}$. So the average sedimentation in the region during the period is $0.063 \mathrm{~m}$. Our result shows that scheduled measurement leads to a reliable prediction concerning sedimentation and erosion.

\section{Acknowledgements}

This study was partly supported by a 2020 research grant from the Public Interest Incorporated Foundation Wesco Promotion of Learning Foundation.

\section{Conflicts of Interest}

The authors declare no conflicts of interest regarding the publication of this paper.

\section{References}

Damage Situation and so Forth Concerning July 2020 Heavy Rain Disaster as of January $7^{\text {th }}, 2021,14: 00$, Cabinet Office, Government of Japan (令和 2 年 7 月豪雨による被害 状況等について, 令和 3 年 1 月 7 日 14:00 分現在, 内閣府). (In Japanese) http://www.bousai.go.jp/updates/r2 07ooame/pdf/r20703 ooame 40.pdf

Iwakami, S., Tamega, M., Sanada, M., Mohri, M., Iwakami, Y., Jimbo, S., Watanabe, M. (2020). Study of Underwater Topography Change with Measurement and Analysis. International Conference on Advanced Information Scientific Development (ICAISD), Journal of Physics: Conference Series, 1641, Article ID: 012003. 
https://doi.org/10.1088/1742-6596/1641/1/012003

https://iopscience.iop.org/article/10.1088/1742-6596/1641/1/012003/pdf

Situation of Damages and so Forth Concerning 2019 Typhoon 19, as of April 10 $0^{\text {th }}$ 9:00, Cabinet Office, Government of Japan (令和元年台風第 19 号等に係る被害状況等に ついて, 令和 2 年 4 月 10 日 9 時 00 分現在, 内閣府). (In Japanese) http://www.bousai.go.jp/updates/r1typhoon19/pdf/r1typhoon19 45.pdf

Summary and Characteristic of Damage in 2018 Japan Floods, Material 2-1, Ministry of Land, Infrastructure, Transport and Tourism (平成 30 年 7 月豪雨災害の概要と被害 の特徵，資料 2-1，国土交通省). (In Japanese)

https://www.mlit.go.jp/river/shinngikai blog/hazard_risk/dai01kai/dai01kai siryou2-1. pdf 